\title{
Suicidal Behavior and Associated Factors Among Students in Mettu University, South West Ethiopia, 2019: An Institutional Based Cross-Sectional Study
}

This article was published in the following Dove Press journal:

Psychology Research and Behavior Management

\section{Zakir Abdu (D) \\ Mohammedamin Hajure (iD Defaru Desalegn}

Department of Psychiatry, Faculty of Health and Medical Sciences, Mettu University, Mettu, Ethiopia

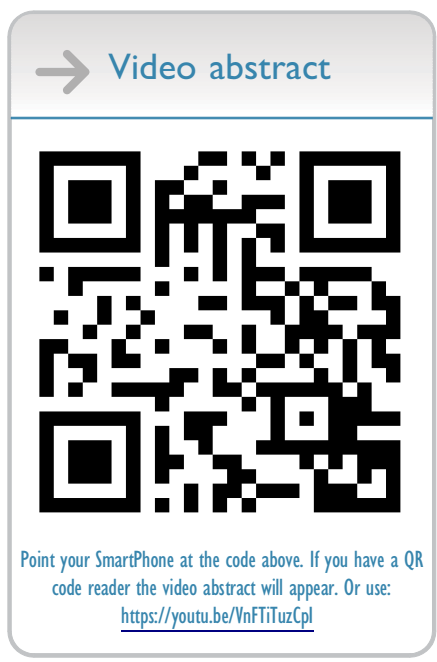

Correspondence: Zakir Abdu; Mohammedamin Hajure

Department of Psychiatry, Faculty of Health and Medical Sciences, Mettu University, P.O. Box: 318, Mettu, Ethiopia Email zakirabdu45@gmail.com; sikoado340@gmail.com
Background: Suicidal behavior is a leading cause of injury and death worldwide. It is a public health issue that is estimated to contribute more than $2.4 \%$ to the global burden of disease by the year 2020. University and college students are among groups affected more than the general population. However, there is a scarcity of studies on the magnitude and associated factors of suicidal behavior among University students in Ethiopia, particularly in Mettu University. Therefore, we assessed the prevalence of suicidal behavior and associated factors among Mettu University students.

Methods: Institution-based multistage stratified cross-sectional study design was conducted among 523 regular main campus students of Mettu University. The Suicidal Behaviors Questionnaire Revised (SBQ-R) was used to screen the presence of suicidal behavior symptoms. Data analysis was done using SPSS version 20.

Results: Lifetime prevalence of suicidal ideation, plan, and attempt was $58.3 \%, 37.3 \%$, and $4.4 \%$, respectively, with one-year prevalence of suicidal ideation at $34 \%$. The multivariate logistic regression analysis revealed that the odds of suicidal ideation were higher among female gender, students who had poor social support, family history of suicide attempt, lifetime alcohol use, rural residence, and less frequently engaging in religious practice; these factors were significantly associated with suicidality.

Conclusion: Nearly one-fourth of respondents report suicidal behavior. Prevalence of suicide was found to be higher. Prevention and coping actions regarding identified factors to reduce burden of suicide are needed.

Keywords: suicidal behavior, prevalence, Mettu University, students

\section{Introduction}

Suicide is a growing public health problem all over the world. ${ }^{1}$ Everyone just as dead from suicide as you are from cancer. ${ }^{2}$ According to the World Health Organization (WHO) about one million people worldwide die of suicide every year (mean mortality rate: 16 per 100,000), that is, one death every 40 seconds. This figure is estimated to increase to 1.53 million deaths by suicide in the year 2020, with one death every 20 seconds and one suicide attempt occurring every one to two seconds. ${ }^{3,4}$

Adolescence and young adulthood carry a risk for suicidal behaviors. ${ }^{5,6}$ About 1 million people worldwide commit suicide each year and college and university students with suicidal ideation are at high risk of suicide. ${ }^{7}$ Suicide is the leading cause of death among college and university students and it accounts for $19 \%$ of all 
deaths for this population. ${ }^{8}$ Studies have confirmed that suicide ranks as the first or second leading cause of death among college and university students. ${ }^{9-11}$

In general, the prevalence of suicidal behaviors among college students ranged from $1.3 \%$ to $32.7 \%{ }^{12,13}$ About 1100 college students die by suicide each year. ${ }^{13}$ Furthermore, about $6.4 \%$ to $9.5 \%$ of college/university students seriously consider suicide, and $1.3 \%$ to $1.5 \%$ made a suicide attempt at the end of the school year. ${ }^{13}$ In university students, suicidal ideation may present at a particularly important moment, due to leaving adolescence and entering the young adult age and the adversities experienced in academic life. ${ }^{10}$

Methods of suicide are drug overdose, poisoning, hanging, jumping into wells and others. ${ }^{3}$ The top three methods used in suicides of young people include firearm (46\%), suffocation (37\%), and poisoning (8\%). Most adolescents used hanging as a method of attempting suicide in both sexes with a higher preference in males, but poisoning was preferred by females. ${ }^{11,14}$

One study conducted in Europe reported the prevalence of suicidal thoughts and behavior in college students in eight different countries and revealed that $32.7 \%$ of the participants had lifetime prevalence of suicidal ideation, $17.5 \%$ suicide plans, and $4.3 \%$ had attempted suicide. Furthermore, the 12-month prevalence of suicidal ideation was $17.2 \%$, suicide plans $8.8 \%$, and suicide attempts $1.0 \%{ }^{15}$ A study done at Cambridge University revealed that the lifetime prevalence of suicidal ideation, plans, and attempts was $22.3 \%, 6.1 \%$, and $3.2 \%$, respectively. For 12 -month prevalence, this was $10.6 \%, 3.0 \%$, and $1.2 \%$, respectively. ${ }^{6}$

A study done in Swaziland among school-going adolescents showed that $18.3 \%$ of 1866 females and $15.6 \%$ of 1672 males students had suicidal behavior. ${ }^{16}$ One result from the University of Maryland revealed that $11.4 \%$ of college students seriously considered attempting suicide in the past year and $7.9 \%$ made suicide ideation. ${ }^{9}$ Two results from Brazil indicated that the prevalence of suicidal ideation is $9.9 \%$ and $12.5 \% .^{10,17}$

Two studies in China reported suicide among university students' accounts $10.72 \%{ }^{7}$ and $19 \%{ }^{8}$ A study conducted in Iran confirmed $4.1 \%$ of 1517 students had thoughts of suicide. ${ }^{15}$ In India, the lifetime prevalence of suicidal ideation among university students is $11.7 \%$, and in Pakistan, the overall rate of suicidal ideation is $31.4 \%{ }^{18}$

One study in Sub-Saharan countries showed that Zambia had the highest prevalence of suicidal ideation (31.9\%) among all students, followed by Kenya (27.9\%),
Botswana (23.1\%), Uganda (19.6\%), and Tanzania $(11.2 \%) .{ }^{19}$ A study done in Ghana showed the prevalence of suicidal behavior in a university was $18.2 \%$ for suicidal ideation, $22.5 \%$ for suicidal plans and $22.2 \%$ for suicidal attempts. ${ }^{20} \mathrm{~A}$ study conducted in Uganda showed that $21.6 \%$ of participants had considered suicidal behavior in the past 12 months. ${ }^{21}$ One study conducted in Tanzania revealed that $7 \%(n=149)$ of students attending high school had thought about suicide with $6.3 \%(n=136)$ having created a plan to carry out an attempt. ${ }^{22}$

One study carried out by WHO showed that risk factors for suicidal behaviors in both developed and developing countries include female sex, younger age, unmarried status, and having a mental illness. ${ }^{23}$

The suicidal behavior of university students cannot be regarded as an issue only for students and their families; it impacts all society and the majority of the population in the university was founded in the productive age. However, little has been explored about suicidal behavior and associated factors among students at the national level, especially at Mettu University. Therefore, this study aimed to assess the prevalence of suicidal behavior and its associated factors among students of Mettu University, Southwest Ethiopia.

\section{Materials and Methods}

\section{Study Setting}

This is an institutional based cross-sectional study conducted in Mettu University from April to June 2019. Mettu University is one of the higher institutions in Ethiopia, and is a third generation university. It is found in Mettu town which is the capital town of Ilu Aba Bor administrative zone of Oromia Regional State and it is located $600 \mathrm{~km}$ southwest of the capital city, Addis Ababa. Mettu University established in 2011. Mettu University currently has two $^{2}$ campuses. The main campus is a study area containing 7 faculties: the faculty of health science, the faculty of natural and computational science, the faculty of social science and humanity, and the school of law. The campus has a total of 43 departments and 8290 regular undergraduate students.

\section{Study Population}

All regular undergraduate students of Mettu University were included in the sample during the data collection period. In our study, the inclusion criteria were all regular undergraduate students at the main campus of Mettu University and the exclusion criterion was regular students 
who are critically ill and unable to read and write because of illness during data collection.

\section{Sample Size}

The minimum number of sample size required for this study was determined by using the formula to estimate single population proportion, $n=\left((\mathrm{z} \quad \alpha / 2)^{2} \mathrm{p}(1-\mathrm{p})\right) / \mathrm{d}^{2}$ by using the following assumptions: prevalence of suicidal ideation among students of the University of Gondar in Ethiopia was $19.9 \%,{ }^{13}$ a $95 \%$ confidence interval (CI), 5\% margin of error, and a non-response rate of $10 \%$. We applied the single population proportion formula to give $\mathrm{n}=(1.96)^{2} \times 0.199(1-0.199) /(0.05)^{2}=245$.

The total number of regular students in the main campus is 8290 , which is less than 10,000 . Hence, using finite population correction formula, the final sample size was calculated as: $\mathrm{nf}=\mathrm{ni} /(1+\mathrm{ni} / \mathrm{N})$, where $\mathrm{n}_{\mathrm{f}}=$ final sample size; $\mathrm{n}_{\mathrm{i}}=$ initial sample size calculated above (245); $\mathrm{N}=$ total number of regular students; hence, $\mathrm{nf}=245 /(1+$ $245 / 8290)=238$.

Since multistage stratified sampling technique was used to select students, using design effect the sample size was multiplied by 2 , giving 476 , considering that the questionnaire was self-administered, and finally adding a $10 \%$ non-response rate, the final number of the study subject became 523 .

\section{Sampling Technique}

The multi-stage stratified sampling technique was used to select the study participants. Stratification was first done on the faculty/college level, then by the department and finally by the year of study.

\section{Data Collection Procedure and Tools}

A self-administered structured questionnaire was used to collect information. Questionnaires about demographics, family, and campus-related and chronic illness factors were developed after an extensive review of the literature and similar study tools. Suicide Behavior Questionnaire Revised (SBQ-R) was made up of the four-item developed by. ${ }^{24}$ The phrasing of each item was such that it asked about different aspects of suicidal behaviors (i.e. ideation/ thoughts, plan/planning, threats, and attempts). The first item explored whether the respondent had ever had thoughts of suicide or engaged in suicidal behaviorin his/ her lifetime (i.e. have you ever thought about or attempted to kill yourself?). In the current study, specifically for lifetime suicidal ideation, item 1 question \#2 was used; for suicidal plan, item 1 questions \#3a and \#3b were used; and for suicidal attempt, item 1 questions \#4a and \#4b were used.

The second question evaluated how frequently, over the preceding 12 months, the respondent had been having ideations of suicide (i.e. how often have you thought about killing yourself in the past year?). The third question enquired about threats to engage in suicidal behavior (i.e. have you ever told someone that you were going to commit suicide, or that you might do it?). The last question explored the participants' self-reported likelihood of engaging in a suicidal behavior in the future (how likely is it that you will attempt suicide someday?). A recent validation study among Nigerian university students showed Cronbach's alpha of 0.80 , indicating the SBQ-R as a reliable screening tool in non-clinical samples in West Africa. ${ }^{25} \mathrm{~A}$ broad range of information is obtained with a very brief administration and it has a sensitivity of $93 \%$, a specificity of $95 \%$ with a score of 3-18 and cutoff point $\geq 7$ for the adult general population. ${ }^{26}$

BDI-II was used to screen for the presence and absence of depression. ${ }^{6}$ BDI has a high degree of sensitivity (0.98) and specificity $(0.95)$ for detecting depression. ${ }^{27}$ It is valid and reliable to assess the presence and absence of depression. ${ }^{24}$ The internal consistency (Cronbach's $\alpha$ ) was higher in many countries ranging from 0.75 to 0.92 . Every item: 0-3 scores, global score: $0-63 .{ }^{24}$

The OSLO-3 social support scale was used, but assessment based on the mean score of individual students. A sum index was made by summarizing the raw scores, the sum ranging from 3 to 14 . A mean score of below 6.7 is poor support, and a mean score of 6.7 and above was good social support. It was reliable in the study (Cronbach's $\alpha=0.91$ ) done at Woloyta University. ${ }^{25}$ Then, this questionnaire was translated to Amharic and Afan Oromo language then retranslated back to English so as to see and keep the consistency. The English version of the questionnaire was used for actual data collection.

\section{Data Processing and Analysis}

Collected data were checked, coded, and entered into Epi Data Version 3.1. Then, the data were exported to the Statistical Package for Social Science Version 23.0 for further analysis. For the analysis of obtaining data simple descriptive statistics were used. Bivariate analysis was used to determine the significance of the association. Variables that showed strong association in bivariate analysis were entered into multivariate logistic regressions to 
control for confounders and the significance of the association was determined by $95 \%$ confidence interval.

\section{Data Quality Control}

To identify potential problems and to make important modifications, the questionnaire was pre-tested on $5 \%$ of the total study participants randomly selected in the same population outside the study area in the College of Agriculture of Mettu University on Bedelle campus one week before the actual data collection date. The prepared questionnaire was checked thoroughly for its completeness, objective and variables before it was distributed to respondents. Also, the collected data were checked for completeness and to take immediate action in detecting cases. The supervisor was eight first degree holders instructor. A pre-test was done after training was given to the supervisors on how to supervise data collection and make a diagnosis of detected cases. At the end of each data collection day, the principal investigator also checked the completeness of filling questionnaires. Any error, ambiguity, incompleteness, or other encountered problem were addressed immediately after the supervisor received the completed questionnaire from each student.

\section{Assessment}

Suicidal behaviors: = individuals who scored SBQ-R 7 and above were labeled as high risk, and below 7 as low risk. $^{26}$

Depression: Depression was scored according to BDIIIthe instrument. BDI-II has 21 items and every item has 0-3 scores with a global score of 0-63. Participants who scored 14 and more were considered to be depressed while participants who scored 13 or lower were not depressed. ${ }^{24}$

Level of social support: The OSLO-3 social support scale was used. ${ }^{25}$ For this study social support is measured based on the mean score of students.

- Poor support - students with a mean score of below 6.7 .

- Good support and - students with a mean score of 6.7 and above.

Chronic illness: Illnesses that can be managed, but cannot be cured, and have a greater risk of developing suicidal behavior, for example, heart diseases, diabetic mellitus, HIV/AIDS, and past mental illness. The response to chronic illness is from the self-report of the participants.
Substance use: Use of any substances mentioned such as alcohol, cigarette, and khat.

Lifetime substance use: Use of alcohol, cigarette, khat, etc., once or more in the participant's lifetime.

Practicing religion: Participants who pray by their religion, explained as follows:

Regular practicing religion: participants who pray daily.

Sometimes practicing religion: participants who do not pray daily.

Truancy: Students were considered truant if they missed more than 3 days of school within the reference period. ${ }^{22}$

University students: Students who are enrolled or attending their education in Mettu University in 2018.

Critically ill: Participants complaining of pain due to any type of illness or objectively known as being ill and unable to read and write because of illness during data collection. Critical illness was decided by trained supervisors as they identify participants with illness before distributing the questionnaires.

\section{Ethical Clearance}

The study was carried out after ethical clearance was obtained from the ethical review board of the faculty of health and medical sciences of Mettu University. An official letter was obtained from Mettu University president's office, and an approbation letter was obtained from the head of the department of psychiatry. Selected students were told about the nature, purposes, benefits, and adverse effects of the study and were invited to participate. Confidentiality was ensured and all related questions they raised were answered.

\section{Results}

\section{Socio-Demographic Characteristics of the Study Participants}

A total of 523 participants were recruited for the study, which makes the response rate $100 \%$. The mean $( \pm \mathrm{SD})$ age of the respondents was $21( \pm 2.2)$ years. Among the respondents, $374(71.5 \%)$ were in the age range of 18-22 years, $270(51.6 \%)$ were male, $306(58.5 \%)$ were from rural backgrounds, $214(40.9 \%)$ and $152(29.1 \%)$ were protestant and orthodox religion followers, respectively (Table 1).

More than half of the participants reported having drunk alcohol in their lifetime and less than one-fourth reported current usage. Khat and tobacco use was relatively modest; $18.3 \%$ had chewed khat and $14.9 \%$ had smoked cigarettes (Table 2). 
Table I Socio-Demographic Characteristics of Mettu University Students, Mettu, South West Ethiopia, 2019 ( $n=523)$

\begin{tabular}{|l|l|l|l|}
\hline Variable & Category & Frequency & Percentage \\
\hline Sex & Male & 270 & 51.6 \\
& Female & 253 & 48.4 \\
\hline Age (in years) & & $21( \pm 2.2)$ & \\
\hline Residence & & & \\
\hline \multirow{2}{*}{ Ethnicity } & Urban & 217 & 41.5 \\
& Rural & 306 & 58.5 \\
\hline Religion & Oromo & 321 & 61.4 \\
& Amhara & 117 & 22.4 \\
& Tigre & 41 & 7.8 \\
& Gurage & 25 & 4.8 \\
& Others* & 19 & 3.6 \\
\hline Family Marital & Protestants & 214 & 40.9 \\
& Orthodox & 152 & 29.1 \\
& Muslim & 137 & 26.2 \\
& Others** & 20 & 3.8 \\
\hline & Living & 395 & 75.5 \\
& together & & \\
& Separated & 64 & 12.2 \\
& Divorced & 24 & 4.6 \\
& Widowed & 40 & 7.6 \\
\hline
\end{tabular}

Notes: *Silte, Agnuak, Kafa, Walayita, Dawuro; **Catholic, Wakeffata.

\section{Prevalence of Suicidal Behavior}

The overall estimate of suicidal behavior among university students was $28.9,95 \%$ CI (25.0-32.5) using SBQR. The lifetime prevalence of suicidal ideation, plan, and attempt was $58.3 \%, 37.3 \%$, and $4.4 \%$, respectively. The prevalence of suicidal ideation over the last 12 months was $34 \%$. No significant gender differences were found in SBQ-R total score. Lifetime prevalence of suicidal ideation was $27.2 \%$ for males and $31.2 \%$ for females, suicide plan was $21.8 \%$ for males and $15.5 \%$ for females, and suicide attempt was $2.7 \%$ for males and $1.7 \%$ for females.

Prevalence of suicidal ideation was high among male (162 (31.0\%)) when compared to female 143 (27.3\%) students. But suicide attempts were high among female (13 (2.5\%)) when compared to male (10 (1.9\%)) students. Prevalence of suicidal plan was somewhat the same between both genders (Table 3).

Prevalence of suicidal ideation, plan, and attempt was high among those students who had poor social support when compared to students who had good social support (Table 4).
Table 2 Frequency Distribution of Substance Related and Psychosocial Factors Among Students of Mettu University, Mettu, South West Ethiopia, $2019(n=523)$

\begin{tabular}{|c|c|c|c|}
\hline Variable & Category & Frequency & Percentage \\
\hline Year of Study & $\begin{array}{l}\text { First } \\
\text { Second } \\
\text { Third } \\
\text { Fourth } \\
\text { Fifth }\end{array}$ & $\begin{array}{l}130 \\
133 \\
107 \\
77 \\
76\end{array}$ & $\begin{array}{l}24.9 \\
25.4 \\
20.5 \\
14.7 \\
14.5\end{array}$ \\
\hline Religious Practice & $\begin{array}{l}\text { Yes } \\
\text { No }\end{array}$ & $\begin{array}{l}342 \\
181\end{array}$ & $\begin{array}{l}65.4 \\
34.6\end{array}$ \\
\hline $\begin{array}{l}\text { Missing Class in the Past } \\
30 \text { Days }\end{array}$ & $\begin{array}{l}\text { None } \\
\text { 1-2 days } \\
3 \text { or more } \\
\text { days }\end{array}$ & $\begin{array}{l}329 \\
149 \\
45\end{array}$ & $\begin{array}{l}62.9 \\
28.5 \\
8.6\end{array}$ \\
\hline $\begin{array}{l}\text { Frequency of Religious } \\
\text { Practice }\end{array}$ & $\begin{array}{l}\text { Always } \\
\text { Sometimes }\end{array}$ & $\begin{array}{l}432 \\
91\end{array}$ & $\begin{array}{l}82.6 \\
17.4\end{array}$ \\
\hline Social Support & $\begin{array}{l}\text { Poor } \\
\text { Good }\end{array}$ & $\begin{array}{l}277 \\
246\end{array}$ & $\begin{array}{l}53.0 \\
47.0\end{array}$ \\
\hline $\begin{array}{l}\text { Alcohol } \\
\text { Lifetime use } \\
\text { Current use }\end{array}$ & $\begin{array}{l}\text { Yes } \\
\text { Yes }\end{array}$ & $\begin{array}{l}299 \\
127\end{array}$ & $\begin{array}{l}57.2 \\
42.5\end{array}$ \\
\hline $\begin{array}{l}\text { Cigarette } \\
\text { Lifetime } \\
\text { Current use }\end{array}$ & $\begin{array}{l}\text { Yes } \\
\text { Yes }\end{array}$ & $\begin{array}{l}78 \\
53\end{array}$ & $\begin{array}{l}14.9 \\
67.9\end{array}$ \\
\hline $\begin{array}{l}\text { Khat } \\
\text { Lifetime use } \\
\text { Current use }\end{array}$ & $\begin{array}{l}\text { Yes } \\
\text { Yes }\end{array}$ & $\begin{array}{l}98 \\
67\end{array}$ & $\begin{array}{l}18.3 \\
68.4\end{array}$ \\
\hline
\end{tabular}

\section{Factors Associated with Suicidal Ideation} Among University Students

As shown in Table 5, in binary logistic regression, suicidal behavior was positively associated with depression (crude odd ratio $(\mathrm{COR})=1.53 ; 95 \% \mathrm{CI}(1.05,2.24))$, poor social support $(\mathrm{COR}=1.64 ; 95 \% \mathrm{CI}(1.11,2.41))$, family history of suicide attempt $(\mathrm{COR}=3.59 ; 95 \% \mathrm{CI}(2.34,5.52))$, lifetime alcohol use $(\mathrm{COR}=1.56 ; 95 \% \mathrm{CI}(1.07,2.28))$, rural residence $(\mathrm{COR}=$ 2.39 ; $95 \% \mathrm{CI}(1.57,3.65))$, being in the first year of study $(\mathrm{COR}=1.68 ; 95 \% \mathrm{CI}(1.01,2.78))$, and less frequently engaging in religious practice $(\mathrm{COR}=1.93 ; 95 \% \mathrm{CI}(1.11,3.35))$.

However, multivariate logistic regression analysis revealed that the odds of suicidal behavior were higher among female gender $(\mathrm{AOR}=1.54 ; 95 \% \mathrm{CI}(1.01,2.36))$, poor social support $(\mathrm{AOR}=1.66 ; 95 \% \mathrm{CI}(1.09,2.53))$, family history of suicide attempt $(\mathrm{AOR}=4.29 ; 95 \% \mathrm{CI}$ $(2.69,6.84))$, lifetime alcohol use $(\mathrm{AOR}=1.65 ; 95 \% \mathrm{CI}$ $(1.09,2.52))$, rural residence $(\mathrm{AOR}=2.66 ; 95 \% \mathrm{CI}(1.68$, 
Table 3 Lifetime Prevalence Estimates of Suicidal Behavior (i.e. Ideation, Plan and Attempts), Suicidal Behavior Risk and Chi-Square Test for Sociodemographic Variables Among Students of Mettu University, Mettu, South West Ethiopia, 2019 ( $n=523)$

\begin{tabular}{|c|c|c|c|c|c|c|c|}
\hline \multirow[t]{3}{*}{ Variable } & \multirow{3}{*}{$\begin{array}{l}\text { Ideation } \\
\mathrm{N}(\%) 305 \text { (58.3\%) }\end{array}$} & \multirow{3}{*}{$\begin{array}{l}\text { Plan } \\
\text { N (\%) } 195(37.3 \%)\end{array}$} & \multirow{3}{*}{$\begin{array}{l}\text { Attempts } \\
\mathrm{N}(\%) 23(4.4 \%)\end{array}$} & \multicolumn{2}{|c|}{ Suicidal Behavior Risk } & \multirow[t]{3}{*}{$\chi^{2}$} & \multirow[t]{3}{*}{$P$-value } \\
\hline & & & & High & Low & & \\
\hline & & & & $N(\%) \quad 15 \mid(28.9 \%)$ & N (\%) 372 (71.1\%) & & \\
\hline \multicolumn{8}{|l|}{ Gender } \\
\hline Male & $162(31.0 \%)$ & 98 (18.7\%) & $10(1.9 \%)$ & $92(17.6 \%)$ & $178(34.0 \%)$ & 0.119 & 0.007 \\
\hline Female & $143(27.3 \%)$ & 97 (18.5\%) & $13(2.5 \%)$ & $59(11.3 \%)$ & $194(37.1 \%)$ & & \\
\hline \multicolumn{8}{|l|}{ Residence } \\
\hline Rural & I84 (35.2\%) & $|2|(23.2 \%)$ & $14(2.7 \%)$ & $113(21.6 \%)$ & $206(39.4 \%)$ & 0.181 & 0.000 \\
\hline Urban & $12 \mid(23.1 \%)$ & $74(14.1 \%)$ & $9(1.7 \%)$ & $38(7.3 \%)$ & $166(31.7 \%)$ & & \\
\hline \multicolumn{8}{|l|}{ Ethnicity } \\
\hline Oromo & $202(38.6 \%)$ & $106(20.3 \%)$ & $13(2.5 \%)$ & $86(16.4 \%)$ & $235(\%)$ & 0.078 & 0.532 \\
\hline Amhara & 61 (11.7\%) & 50 (9.6\%) & $6(1.2 \%)$ & 39 (7.5\%) & 78 (I4.9\%) & & \\
\hline Tigre & $20(3.8 \%)$ & 17 (3.3\%) & 4 & $13(2.5 \%)$ & 28 (5.4\%) & & \\
\hline Gurage & $12(2.3 \%)$ & $13(2.5 \%)$ & 0 & $9(1.7 \%)$ & $16(3.1 \%)$ & & \\
\hline Others* & $10(1.9 \%)$ & $9(1.7 \%)$ & 0 & $4(2.9 \%)$ & 15 (2.9\%) & & \\
\hline \multicolumn{8}{|l|}{ Religion } \\
\hline Protestant & 125 (23.9\%) & 83 (15.9\%) & $6(1.2 \%)$ & 65 (12.4\%) & 149 (28.5\%) & 0.076 & 0.386 \\
\hline Orthodox & 86 (16.4\%) & 62 (11.8\%) & 4 & 37 (7.1\%) & 115 (22.0\%) & & \\
\hline Muslim & $84(16.1 \%)$ & 40 (7.6\%) & $13(2.4 \%)$ & 41 (7.8\%) & $96(18.4 \%)$ & & \\
\hline Others** & $10(1.9 \%)$ & $10(1.9 \%)$ & 0 & $8(1.5 \%)$ & $12(2.3 \%)$ & & \\
\hline \multicolumn{8}{|l|}{ Year of Study } \\
\hline First & $24(4.6 \%)$ & $25(4.8 \%)$ & $13(2.5 \%)$ & 61 (11.7\%) & $16 \mid(30.8 \%)$ & 0.221 & 0.000 \\
\hline Second & $19(3.6 \%)$ & 17 (3.3\%) & 2 & $50(9.6 \%)$ & $55(10.5 \%)$ & & \\
\hline Third & $34(6.5 \%)$ & $14(2.7 \%)$ & II (2.1\%) & $32(6.1 \%)$ & $122(23.3 \%)$ & & \\
\hline Fourth & 0 & 4 & 4 & 2 & $5(1.0 \%)$ & & \\
\hline Fifth & 4 & 0 & 0 & $6(1.1 \%)$ & 29 (5.5\%) & & \\
\hline \multicolumn{8}{|l|}{ Family Marital Status } \\
\hline Living together & $225(43.0 \%)$ & I52 (29.1\%) & 18 (3.4\%) & 117 (22.4\%) & 278 (53.2\%) & 0.127 & 0.0047 \\
\hline Separated & $33(6.3 \%)$ & $27(5.1 \%)$ & 4 & $19(3.6 \%)$ & 45 (8.6\%) & & \\
\hline Divorced & 10 (1.9\%) & $13(2.5 \%)$ & 1 & $6(1.1 \%)$ & I8 (3.4\%) & & \\
\hline Widowed & 37 (7.1\%) & 3 & 0 & $9(1.7 \%)$ & 31 (5.9\%) & & \\
\hline \multicolumn{8}{|l|}{ Faculty/College } \\
\hline Health & $146(27.9 \%)$ & $44(8.4 \%)$ & $12(2.2 \%)$ & $85(16.3 \%)$ & $117(22.4 \%)$ & 0.279 & 0.000 \\
\hline Law & $34(6.5 \%)$ & $31(5.9 \%)$ & 0 & $25(4.8 \%)$ & $40(7.6 \%)$ & & \\
\hline Applied & $58(11.1 \%)$ & $48(9.1 \%)$ & $7(1.3 \%)$ & $17(3.3 \%)$ & $96(18.4 \%)$ & & \\
\hline Technology & $67(12.8 \%)$ & $72(13.8 \%)$ & 4 & $24(4.6 \%)$ & $119(22.8 \%)$ & & \\
\hline
\end{tabular}

Notes: *Silte, Agnuak, Kafa, Walayita, Dawuro; **Catholic, Wakeffata.

4.22)) and less frequently engaging in religious practice $(\mathrm{AOR}=2.49 ; 95 \% \mathrm{CI}(1.35,4.62))$; these factors were significantly associated with suicidal behavior. We found no evidence of associations between suicidal ideation and family relationship status, or personal and family history of physical or mental illness (Table 6).

\section{Discussion}

This study revealed the lifetime prevalence of suicidal ideation, plan, and attempt was $58.3 \%, 37.3 \%$, and $4.4 \%$, respectively, with the prevalence of suicidal ideation over the last 12 months showing 34\%.

The chi-square test showed that subjects belonging to suicidal ideation were more likely to be males $(P=0.007)$, with poor social support $(P=0.012)$, and with alcohol use $(P=0.027)$, which was consistent with a study done in Italy. ${ }^{28}$

The findings of this study showed that prevalence of suicidal ideation, plan, and attempt were $58.3 \%, 37.3 \%$, and $4.4 \%$, respectively, with prevalence of suicidal ideation over the last 12 months showing 34\%. This study 
Table 4 Lifetime Prevalence Estimates of Suicidal Behavior (i.e. Ideation, Plan and Attempts), Suicidal Behavior Risk and Chi-Square Test with Respect to Psychosocial Factor and Substance Use Among Students of Mettu University, Mettu, South West Ethiopia, 2019 $(n=523)$

\begin{tabular}{|c|c|c|c|c|c|c|c|}
\hline \multirow[t]{3}{*}{ Variable } & \multirow{3}{*}{$\begin{array}{l}\text { Ideation } \\
\mathrm{N}(\%) \text { 305(58.3\%) }\end{array}$} & \multirow{3}{*}{$\begin{array}{l}\text { Plan } \\
\text { N (\%) } 195 \text { (37.3\%) }\end{array}$} & \multirow{3}{*}{$\begin{array}{l}\text { Attempts } \\
\mathrm{N}(\%) 23(4.4 \%)\end{array}$} & \multicolumn{2}{|c|}{ Suicidal Behavior Risk } & \multirow[t]{3}{*}{$\chi^{2}$} & \multirow[t]{3}{*}{$P$-value } \\
\hline & & & & High N (\%) & Low N (\%) & & \\
\hline & & & & $151(28.9 \%)$ & $372(71.1 \%)$ & & \\
\hline \multicolumn{8}{|l|}{ Social Support } \\
\hline Poor & $158(30.2 \%)$ & $105(20.1 \%)$ & $14(2.6 \%)$ & $58(11.1 \%)$ & $188(35.9 \%)$ & 0.110 & 0.012 \\
\hline Good & $147(28.1 \%)$ & $90(17.2 \%)$ & $9(1.8 \%)$ & $93(17.8 \%)$ & $184(35.2 \%)$ & & \\
\hline \multicolumn{8}{|l|}{ Frequency of Religious Practice } \\
\hline Sometimes & $202(38.6 \%)$ & $122(23.4 \%)$ & $18(3.4 \%)$ & $133(25.4 \%)$ & 295 (56.4\%) & 0.103 & 0.018 \\
\hline Always & $103(19.7 \%)$ & $73(14.0 \%)$ & $5(1.0 \%)$ & $18(3.4 \%)$ & $77(14.7 \%)$ & & \\
\hline \multicolumn{8}{|l|}{ Lifetime Alcohol Use } \\
\hline No & $140(26.8 \%)$ & 79 (15.1\%) & $5(1.0 \%)$ & $76(14.5 \%)$ & $148(28.3 \%)$ & 0.097 & 0.027 \\
\hline Yes & $165(31.5 \%)$ & $116(12.2 \%)$ & $18(3.4 \%)$ & $75(14.3 \%)$ & $224(42.8 \%)$ & & \\
\hline \multicolumn{8}{|l|}{ Cigarette Smoking } \\
\hline No & 255 (48.8\%) & $174(33.2 \%)$ & $16(3.1 \%)$ & $127(24.3 \%)$ & $318(60.8 \%)$ & 0.151 & 0.018 \\
\hline Yes & $50(9.6 \%)$ & $21(4.0 \%)$ & $7(1.4 \%)$ & $24(4.6 \%)$ & $54(10.3 \%)$ & & \\
\hline \multicolumn{8}{|l|}{ Khat Chewing } \\
\hline No & 249 (47.6\%) & $156(29.8 \%)$ & $20(3.8 \%)$ & 115 (22.0\%) & $310(59.3 \%)$ & 0.065 & 0.698 \\
\hline Yes & $56(10.7 \%)$ & $39(7.4 \%)$ & 3 & $36(6.9 \%)$ & $62(11.9 \%)$ & & \\
\hline \multicolumn{8}{|l|}{ Family History of Suicide Attempt } \\
\hline Yes & $64(12.2 \%)$ & 50 (9.5\%) & $6(1.1 \%)$ & 33 (11.7\%) & 53 (II.3\%) & 0.264 & 0.000 \\
\hline No & $24 \mid(46.1 \%)$ & 145 (27.7\%) & 17 (3.2\%) & $118(17.2 \%)$ & 319 (59.8\%) & & \\
\hline \multicolumn{8}{|l|}{ Depression } \\
\hline Yes & 165 (31.5\%) & 84 (I5.1\%) & 12 (2.3\%) & $50(12.4 \%)$ & $129(37.7 \%)$ & 0.090 & 0.040 \\
\hline No & $140(26.8 \%)$ & III (21.3\%) & II (2.1\%) & 100 (16.4\%) & 118 (33.5\%) & & \\
\hline
\end{tabular}

finding was in line with studies done in Europe and Cambridge University, which found the prevalence of suicidal attempts to be $4.3 \%$ and $3.2 \%,{ }^{6,14}$ respectively. The probable reason for the similarity of findings might be the same tool and design were used both in the current and previous studies. In addition, other reasons might be that the studies were conducted in similar populations.

However, a study conducted among 1654 rural Chinese individuals aged 16-34 years revealed lifetime and one-year suicidal ideation of $45.1 \%$ and $19.3 \%,{ }^{29}$ which was lower than the current study (58.3\% and 34\%). Additionally, our sample shows higher lifetime and past 12-month prevalence of suicidal ideation and planning, compared to studies conducted at Cambridge University, ${ }^{6}$ University of Maryland, ${ }^{9}$ and Belgium. ${ }^{5}$ The discrepancy might be related to tools of study and sociocultural background of the population.

In other words, the prevalence of suicide attempts in our study was higher compared to studies in Brazil 12.5\%, ${ }^{17}$ China $19 \%,{ }^{8}$ Morocco $6.5 \%,{ }^{30}$ and Australian $(4.2 \%)^{4}$ and American populations $(4.1 \%){ }^{31}$ The particularly high suicidal attempt observed in the current sample could partly be explained by the sample size and study design used.

Factors positively associated with suicide were female gender, poor social support, not frequently engaging in religious practice, family history of suicide attempt, rural residence, and lifetime alcohol use.

Sex may significantly affect the prevalence of suicidal behavior. In the current study, the odds of having suicide behavior in female respondents were higher compared to in male respondents, which is in agreement with the results of other published studies in different settings. $7,8,11,12$ The discrepancy might be explained on the basis of gender role socialization theory, which states that females are expected to be dependent and indecisive, and express their stress via rumination, so females have a higher rate of suicide attempts than males. $^{32}$

A study conducted in one college in China indicated that practicing religion is a protective factor for suicidal behavior. ${ }^{33}$ In alignment with this study, our study revealed less frequently engaging in religious practice increases odds 
Table 5 Bivariable Logistic Regression Examining the Associations Between Demographic, Clinical, Substance, Psychosocial Factors; and Suicidal Behavior Among Students of Mettu University, Mettu Town, South West Ethiopia, $2019(n=523)$

\begin{tabular}{|c|c|c|c|c|}
\hline \multirow[t]{2}{*}{ Study Variables } & \multicolumn{2}{|l|}{ Suicide } & \multirow[t]{2}{*}{ COR(95\% Cl) } & \multirow{2}{*}{$\begin{array}{l}P \text { - } \\
\text { value }\end{array}$} \\
\hline & Yes N (\%) & No N (\%) & & \\
\hline \multicolumn{5}{|l|}{ Sex } \\
\hline Male & 59 (23.3\%) & 194 (76.7\%) & Ref & 0.007 \\
\hline Female & 92 (34.1\%) & 178 (65.9\%) & $1.69(1.16,2.49)$ & \\
\hline \multirow{2}{*}{\multicolumn{5}{|c|}{$\begin{array}{l}\text { Lifetime Alcohol } \\
\text { Use }\end{array}$}} \\
\hline & & & & \\
\hline Yes & 76 (33.9\%) & | 48 (66. I\%) & $1.56(1.07,2.28)$ & 0.022 \\
\hline No & 75 (25.1\%) & 224 (74.9\%) & Ref & \\
\hline Social Support & & & & 0.012 \\
\hline Good & $58(23.6 \%)$ & 188 (76.4\%) & I.64 (I.II, 2.4I) & \\
\hline Poor & $93(66.4 \%)$ & $184(66.4 \%)$ & Ref & \\
\hline \multicolumn{5}{|l|}{ Year of Study } \\
\hline Ist year & 65 (29.1\%) & 158 (70.9\%) & $1.68(1.01,2.78)$ & 0.044 \\
\hline 2nd year & $38(40.9 \%)$ & 55 (59.1\%) & $0.67(0.41,1.09)$ & 0.107 \\
\hline 3rd year & $32(21.6 \%)$ & 116 (78.4\%) & $1.74(0.73,4.1 \mathrm{I})$ & 0.209 \\
\hline 4th year & $10(41.7 \%)$ & 14 (58.3\%) & $0.51(0.19,1.27)$ & 0.145 \\
\hline 5th year & $6(17.1 \%)$ & $29(82.9 \%)$ & Ref & \\
\hline \multicolumn{5}{|l|}{ Depression } \\
\hline Yes & $82(33.7 \%)$ & $211(75.4 \%)$ & $1.53(1.05,2.24)$ & 0.028 \\
\hline No & 69 (24.6\%) & $161(66.3 \%)$ & Ref & \\
\hline \multicolumn{5}{|l|}{ Religion Practice } \\
\hline Always & 18 (I8.9\%) & 77 (8I.I\%) & Ref & 0.020 \\
\hline Sometimes & $133(31.1 \%)$ & 295 (68.9\%) & $1.93(1.11,3.35)$ & \\
\hline \multicolumn{5}{|l|}{ Family History of } \\
\hline \multicolumn{5}{|l|}{ Suicide Attempt } \\
\hline Yes & 61 (50.8\%) & 59 (49.2\%) & $3.59(2.34,5.52)$ & $<0.00$ \\
\hline No & 90 (22.3\%) & $313(77.7 \%)$ & Ref & \\
\hline \multicolumn{5}{|l|}{ Residence } \\
\hline Rural & 113 (35.4\%) & $206(64.6 \%)$ & $2.39(1.57,3.65)$ & $<0.001$ \\
\hline Urban & $38(18.6 \%)$ & $166(81.4 \%)$ & Ref & \\
\hline
\end{tabular}

of suicide by 2.49 times. This might be explained by the notion that a variety of stressful events are experienced at higher institution, and different means of resilience can help to cope with stress.

Poor social support was one of the predictors of suicidal behavior in this study. Individuals who had poor social support were 1.66 times more likely to have suicidal behavior than individuals who had strong social support. This was similar to results from a recent study in Maryland, Johns Hopkins University, countries of SubSaharan Africa, China, Tanzania, and Ethiopia., ${ }^{7,9,12,19,22}$ This might be because of the notion that belongingness could protect against suicide is supported by evidence that
Table 6 Multivariable Logistic Regression Examining the Associations Between Demographic, Clinical, Substance, Psychosocial Factors; and Suicidal Behavior Among Students of Mettu University, Mettu Town, South West Ethiopia, 2019 $(n=523)$

\begin{tabular}{|c|c|c|c|c|}
\hline \multirow{2}{*}{$\begin{array}{l}\text { Study } \\
\text { Variables }\end{array}$} & \multicolumn{2}{|l|}{ Suicide } & \multirow[t]{2}{*}{$\operatorname{AOR}(95 \% \mathrm{Cl})$} & \multirow[t]{2}{*}{$P$-value } \\
\hline & Yes N (\%) & No N (\%) & & \\
\hline \multicolumn{5}{|l|}{ Sex } \\
\hline Male & 59 (23.3\%) & 194 (76.7\%) & Ref & 0.049 \\
\hline Female & $92(34.1 \%)$ & 178 (65.9\%) & $1.54(1.01,2.36)$ & \\
\hline \multicolumn{5}{|l|}{ Social Support } \\
\hline Good & $58(23.6 \%)$ & 188 (76.4\%) & Ref & 0.019 \\
\hline Poor & $93(66.4 \%)$ & $184(66.4 \%)$ & $1.66(1.09,2.53)$ & \\
\hline \multicolumn{5}{|l|}{ Lifetime Alcohol } \\
\hline \\
\hline Yes & 76 (33.9\%) & $148(66.1 \%)$ & $1.65(1.09,2.52)$ & 0.018 \\
\hline No & 75 (25.1\%) & 224 (74.9\%) & Ref & \\
\hline \multicolumn{5}{|l|}{ Religion Practice } \\
\hline Always & 18 (18.9\%) & 77 (81.1\%) & Ref & 0.004 \\
\hline Sometimes & $133(3 \mid .1 \%)$ & 295 (68.9\%) & $2.49(1.35,4.62)$ & \\
\hline \multicolumn{5}{|l|}{ Family History } \\
\hline \multicolumn{5}{|l|}{ of Suicide } \\
\hline \multicolumn{5}{|l|}{ Attempt } \\
\hline Yes & 61 (50.8\%) & $59(49.2 \%)$ & $4.29(2.69,6.84)$ & $<0.001$ \\
\hline No & $90(22.3 \%)$ & $313(77.7 \%)$ & Ref & \\
\hline \multicolumn{5}{|l|}{ Residence } \\
\hline Rural & $113(35.4 \%)$ & $206(64.6 \%)$ & $2.66(\mathrm{I} .68,4.22)$ & $<0.001$ \\
\hline Urban & 38 (18.6\%) & $166(81.4 \%)$ & Ref & \\
\hline
\end{tabular}

university students who were members of a fraternity were less likely to report suicide ideation. ${ }^{34}$

Our results indicate that lifetime alcohol use was associated with higher odds of suicidal behavior. Our findings are in line with studies showing a positive relationship between alcohol use and suicidal behavior. ${ }^{11,15,16,22}$ Alcohol use needs a special mention because it increases suicidality by itself, especially when related to adjustment disorders which are a common condition among university students and depression. ${ }^{35}$

Students with a family history of suicidal attempts were 4.29 more likely to have suicidal behavior compared to those without. This was supported by studies conducted in different settings. ${ }^{3,10,11,30}$ Having a close relationship with someone who has a history of suicide attempts can lead to the behavior of the reproduction of the act, becoming conditioned as a way of resolving conflicts, so increasing cases of suicide. ${ }^{28}$

Consistent with a study done in Italy ${ }^{36}$ our results do not confirm previous evidence reporting significant associations between depression and having suicidal behavior. 


\section{Limitations}

This study did not account for the presence of psychiatric or psychological disorders other than depression, such as anxiety, which has been associated with suicide. Due to its cross-sectional nature, the study could not explore the cause and effect relationship of variables. The other limitation of the study is information bias, since the information was collected on self-administered questionnaires. Participants of the study were recruited from only one university, which is Mettu University's main Campus. Another limitation of the study was that students answer the questionnaire in English, and self-report evaluation could increase the prevalence of suicidal behaviors. The other limitation of this study is the lack of investigation of variables like other substances (such as cocaine, heroin, amphetamine), temperament, familial status, or different types of university.

\section{Conclusions}

Nearly half of Mettu University students reported depressive symptoms, and one in four reported suicidal behavior (suicidal ideation, plan, and attempt). In the current study prevalence of suicide among university students was found to be higher than studies conducted in a different setting. Being female, poor social support, lifetime alcohol use, family history of suicide attempt, rural residence, and less frequently engaging in religious practice were identified as independent factors predicting suicide ideation and attempt.

\section{Abbreviations}

CI, confidence Interval; DSM-5, Diagnostic and Statistical Manual of mental disorders Fifth Edition; ETB, Ethiopian Birr; HIV/AIDS, human immune deficiency virus/acquired immune deficiency syndrome; OR, odds ratio; SBQ-R, Suicidal Behavior Questionnaire Revised; SPSS, Statistical Package for Social Science; UK, United Kingdom; US, United States; WHO, World Health Organization.

\section{Ethics Statement}

The study was carried out in accordance with the principles of the Declaration of Helsinki. Ethical clearance is obtained from the ethical review board of faculty of health and medical sciences of Mettu University. An official letter was obtained from Mettu University president's office, and an approbation letter was obtained from the head of the department of psychiatry. Selected students were told about the nature, purposes, benefits, and adverse effects of the study and invited to participate. Confidentiality was ensured and all related questions they raised were answered. All participants were recruited directly in their respective classrooms after the end of a class. They were asked to make $20 \mathrm{~min}$ available for completion of the questionnaires. Participation was completely voluntary, with no economic or other motivation, and each participant signed written informed consent for their participation. Participants' right to refuse or discontinue participation at any time they want was strictly respected. The time of investigation avoided the beginning and end of the semester, when students are undergoing stress related to moving or preparing for final exams and projects. A student who scores more than SBQ-R more than 7 , on the BDI-II more than 20 and had suicidal wishes, thoughts or plans was linked to the student clinic.

\section{Data Sharing Statement}

The datasets used and analyzed during the current study are available from the corresponding author on reasonable request.

\section{Acknowledgments}

We would like to thank Mettu University for providing ethical approval to conduct this research. Our deepest thanks go to all study participants, data collectors, and supervisors who spent their valuable time for the good outcome of the research work.

\section{Author Contributions}

ZA wrote the protocol, design the study, organized the data collection process, analyzed the data, and reviewed and edited the manuscript. DD revised and approved the protocol, participated in data analysis, reviewed and edited the manuscript. MAH contributed to an analysis of the data, drafted the manuscript, critically reviewed and approved the manuscript for publication. All authors contributed to data analysis, drafting or revising the article, gave final approval of the version to be published, and agree to be accountable for all aspects of the work.

\section{Disclosure}

The authors declare that they have no competing interests.

\section{References}

1. Poor FB, Tabatabaei SM, Bakhshani N. Epidemiology of suicide and its associated socio-demographic factors in patients admitted to emergency department of Zahedan Khatam-Al-Anbia Hospital. Int J High Risk Behav Addict. 2014;3(4):e22637. 
2. FRSPH WC. The global crisis of depression: the low of the 21st century? Perspect public health. 2015;135(2):569958.

3. WHO. Preventing Suicide a Global Imperative. World Health Organization; 2014.

4. Rey JM. IACAPAP Textbook of Child and Adolescent Mental Health Editor. International Association for Child and Adolescent Psychiatry and Allied Professions; 2012;86.

5. Mortier P, Kiekens G. A risk algorithm for the persistence of suicidal thoughts and behaviors during college. J Clin Psychiatry. 2017;78 (7):1-22. doi:10.4088/JCP.17m11485

6. Mortier P, Cuijpers P, Kiekens G, Auerbach RP, Demyttenaere K, Green JG. The prevalence of suicidal thoughts and behaviours among college students: a meta-analysis. Psychol Med. 2017;48:1-12.

7. Li ZZ, Li YM, Lei XY, et al. Prevalence of suicidal ideation in Chinese college students: a meta-analysis. PLoS One. 2014;9(10): e104368.

8. Zhai H, Bai B, Chen L, et al. Correlation between family environment and suicidal ideation in university students in China. Int $J$ Environ Res Public Health. 2015;12(2):1412-1424. doi:10.3390/ijerph120201412

9. Giru BW. Prevalence and associated factors of suicidal ideation and attempt among high school adolescent students in Fitche Town, North Shoa, Oromia Region, Ethiopia, 2012: institutional based cross sectional study. J Heal Sci Nurs. 2016;23(3):1-12.

10. Gedeon H, Mirianh P, Paulo PMCD. Factors associated with suicidal ideation among university students 1. Rev Latino-Am Enfermagem. 2017;25.

11. Arria, AM, O'Grady, KE, Caldeira, KM, Vincent, KB, Wilcox HC, Eric W. Suicide ideation among college students: a multivariate analysis. Arch Suicide Res. 2010;13(3):230-246.

12. Hirsch JK, Webb JR, Jeglic EL. Forgiveness, depression, and suicidal behavior among a diverse sample of college students. J Clin Psychol. 2011;67(9):896-906. doi:10.1002/jclp.v67.9

13. Wilcox HC, Arria AM, Caldeira KM, Kathryn B, Pinchevsky GM, Grady KEO. Attempts during college. J Affect Disord. 2011;127(1-3):287-294. doi:10.1016/j.jad.2010.04.017

14. Jacobson L. Suicide and attempted suicide in a general hospital in western Ethiopia. Acta Psychiatr Scand. 1985;71:596-600. doi:10.1111/j.1600-0447.1985.tb02553.x

15. Almansour AM, Siziya S. Suicidal ideation and associated factors among school going adolescents in Swaziland. Afr Health Sci. 2017;17(4):1172-1177. doi:10.4314/ahs.v17i4.26

16. Mortier P, Auerbach RP, Alonso J, et al. Suicidal thoughts and behaviors among first-year college students: results from the WMH-ICS project. J Am Acad Child Adolesc Psychiatry. 2018;57 (4):263-273. doi:10.1016/j.jaac.2018.01.018

17. Mortier P, Cuijpers P, Amsterdam VU, Kiekens G, Auerbach RP. The prevalence of suicidal thoughts and behaviours among college students: a meta-analysis. Psychol Med. 2017;48(4):554-565.

18. Kirchner T, Ferrer L, Forns M, Zanini D. Self-harm behavior and suicidal ideation among high school students. Gender differences and relationship with coping strategies. Actas Esp Psiquiatr. 2011;39 (4):226-235.

19. Palmier JB. Prevalence and correlates of suicidal ideation among students in sub-Saharan Africa. Preval Correl Suicidal Ideation Among. 2011;1-55.
20. Ziaei R, Viitasara E, Soares J, et al. Suicidal ideation and its correlates among high school students in Iran: a cross-sectional study. BMC Psychiatry. 2017;17(1):1-7. doi:10.1186/s12888-017-1298-y

21. Oppong K, Kugbey N, Osafo J, Quarshie EN, Owusu J. The prevalence and correlates of suicidal behaviours (ideation, plan and attempt) among adolescents in senior high schools in Ghana. SSM Popul Health. 2017;3:427-434. doi:10.1016/j.ssmph.2017.05.005

22. Peltzer K, Pengpid S. Suicidal ideation and associated factors among school-going adolescents in Thailand. Int $J$ Environ Res Public Health. 2012;9(2):462-473. doi:10.3390/ijerph9020462

23. Shayo FK, Lawala PS. Does bullying predict suicidal behaviors among in-school adolescents? A cross- sectional finding from Tanzania as an example of a low-income country. BMC psychiatry. 2019;19(1):1-6.

24. Utility C. The Suicide Behaviors Questionnaire-Revised (SBQ-R) Overview. Assessment. 2001;(5):4-6.

25. Uche N, Princewill S. Clinical factors as predictors of depression in a Nigerian prison population. $J$ Psychiatry. 2015;19(1):1-6.

26. Borges G, Nock MK, Abad JMH, et al. Attempts in the WHO World Mental Health Surveys. J Clin Psychiatry. 2011;71(12):1617-1628.

27. Fanta T, Abebaw D, Haile K, Hibdye G, Assefa D. Assessment of quality of life and associated factors among patients with schizophrenia in Ethiopia, 2017. 2018 December:10-18.

28. Nock MK, Borges G, Bromet EJ, Cha CB, Ronald C, Lee S. Suicide and suicidal behavior. Epidemiol Rev. 2008;30(1):133-154. doi:10.1093/epirev/mxn002

29. Shahlaei L, Hasan S, Ahmad N, Kiumarsi S. Review on assessment of depression by Beck Depression Inventory (BDI) and Hamilton depression rating scale. Int $J$ Res. 2014;2:99-107.

30. Ayele TA, Azale T, Alemu K, Abdissa Z. Prevalence and associated factors of antenatal depression among women attending antenatal care service at Gondar University Hospital, Northwest Ethiopia. PloS one. 2016;11(5):1-12.

31. Malakouti SK, Davoudi F, Khalid S, Asl MA. The epidemiology of suicide behaviours among the countries of the eastern mediterranean region of WHO: a systematic review. Acta Med Iran. 2015;53 (5):257-265.

32. Duko B, Gebeyehu A, Ayano G. Prevalence and correlates of depression and anxiety among patients with tuberculosis at Wolaitasodo University Hospital and Sodo Health Center, WolaitaSodo, South Ethiopia, cross sectional study. BMC Psychiatry. 2015;15(1):1-7. doi:10.1186/s12888-015-0598-3

33. Solano P, Aguglia A, Caprino M, et al. The personal experience of severe suicidal behaviour leads to negative attitudes towards self- and other' s suicidal thoughts and behaviours: a study of temperaments, coping strategies, and attitudes towards suicide among medical students. Psychiatry Res. 2019;272:669-675. doi:10.1016/j. psychres.2018.12.116

34. Li H, Luo X, Ke X, et al. Major depressive disorder and suicide risk among adult outpatients at several general hospitals in a Chinese Han population. PloS one. 2017;12(10):1-15.

35. Wang Y, Shi Z, Luo Q. Association of depressive symptoms and suicidal ideation among university students in China. Medicine. 2017;96(13):e6476.

36. Carter MJ. Gender socialization and identity theory. Soc Sci. 2014;3 (2):242-263. 


\section{Publish your work in this journal}

Psychology Research and Behavior Management is an international, peer-reviewed, open access journal focusing on the science of psychology and its application in behavior management to develop improved outcomes in the clinical, educational, sports and business arenas Specific topics covered in the journal include: Neuroscience, memory and decision making; Behavior modification and management; Clinical applications; Business and sports performance management; Social and developmental studies; Animal studies. The manuscript management system is completely online and includes a very quick and fair peer-review system, which is all easy to use. Visit http://www. dovepress.com/testimonials.php to read real quotes from published authors.

Submit your manuscript here: https://www.dovepress.com/psychology-research-and-behavior-management-journal 